\title{
LA DUALIDAD DE LA MODERNIDAD RIESGOS INEVITABLES DEL DESARROLLO TECNOLÓGICO
}

\author{
J. Jesús Aguiar Miramontes*
}

\begin{abstract}
Aguiar-Miramontes J.J. La dualidad de la modernidad riesgos inevitables del desarrollo tecnológico. Hitos de Ciencias Económico Administrativas 2013;19 (54): 87-92.

RESUMEN
\end{abstract}

En este texto se presentan algunas definiciones para entender el concepto de modernidad, así como varios de los riesgos inherentes a ella. Con el desarrollo y evolución de las sociedades han surgido nuevos retos a los cuales ha sido difícil encontrar solución, por ejemplo, el deterioro ambiental. Asimismo se argumenta que la inevitabilidad con la que son vendidos los riesgos del desarrollo y el progreso es y debe ser discutible, sobre todo cuando se pone en peligro la existencia de la humanidad.

\author{
Aguiar-Miramontes J.J. The duality of \\ the modernity. Inevitable risks of technological \\ development. Hitos de Ciencias Económico \\ Administrativas 2013;19 (54): 87-92.
}

\section{ABSTRACT}

In this paper some definitions to understand the concept of modernity are shown, as well as several of the risks inherent to it. With the development and evolution of societies new challenges have emerged whose solutions have been difficult to find, for example, the environmental degradation. Here it is argued that the inevitability with which the risks of development and progress are sold is and must be debatable, especially when it threatens the existence of mankind.

Palabras claves: Modernidad. Dualidad. Riesgo. Key words: Modernity. Duality. Risk. Inevitable. Modern Inevitable. Sociedad moderna. society.

DIRECCIÓN PARA RECIBIR CORRESPONDENCIA: Correo electrónico: jesus-aguiar@hotmail.com

Lo inevitable jamás sucede; lo inesperado siempre.

$$
\text { John Maynard Keynes. }
$$

a conformación del mundo actual está definida en términos de desarrollo tecnológico, avance de la ciencia, cambio en el modus vivendi de la sociedad y en las formas en que esta última interactúa consigo misma y con el mundo. Las mejoras del industrialismo propiciaron un adelanto en la manera de resolver los problemas que la sociedad enfrenta en su constante búsqueda de progreso, felicidad, comodidad y éxito; es decir, en su deseo de vivir «mejor», más «seguros» y por más tiempo. Así, hemos sido testigos de incuestionables avances en genética, biotecnología, comunicaciones, armamento (nuclear, químico, biológico) y medicina.

Sin embargo, los progresos científicos tienen también su lado oscuro y, en este sentido, el lado oscuro del desarrollo tecnológico está representado por los riesgos y contingencias que amenazan ya no a la continuidad del progreso de la sociedad, sino a la existencia de la misma. El sociólogo alemán Ulrich Beck utiliza el nombre de modernidad reflexiva para designar esta situación, en la que progreso y destrucción son caras de una misma luna -uno luminoso y visible, el otro oculto y oscuro-. Así, la modernidad reflexiva implica la posibilidad de una creativa autodestrucción de una

* Departamento de Ciencias Económico-Administrativo. Instituto Tecnológico de Tepic. 
época completa: la sociedad industrial (Beck, 1998). En esta nueva etapa, el progreso se convierte en destrucción. El «sujeto» de esta destrucción creativa no es la revolución, ni la crisis, sino la modernización occidental (Giddens, 1994).

El eje central de este artículo girará en torno al desarrollo de las características de la modernidad, sus riesgos, sus consecuencias, así como un análisis del por qué estas dos últimas particularidades se han vuelto centrales en la comprensión del mundo moderno. Lo anterior tiene como finalidad, por una parte, poner a debate si la modernidad es un fenómeno que deviene paradójico e inevitable (por la auto-destrucción inherente al progreso que la caracteriza) y, por otra, si la modernidad resulta tener como adjetivo que la califica a la dualidad: una modernidad que por un lado es perceptible por su luminosidad (avances científicos) y, por el otro, permanece oculta en las tinieblas (riesgos), lo cual no significa que no exista ese lado oscuro.

\section{¿Qué es la modernidad?}

El periodo de la modernidad es designado por distintos autores como la época en la cual el iluminismo y el desarrollo industrial han producido transformaciones drásticas. En ese sentido, Anthony Giddens apunta que la modernidad podría ser definida, en un primer momento, como los modos de vida u organización social que surgieron en Europa desde el siglo XVII en adelante (Giddens, 2002). Esto sirve como referencia para señalar que la modernidad es el inicio de una etapa en que la organización tradicional de la sociedad (en feudos) fue sustituida por la creación de Estados-nación, a lo que le siguió la erradicación del derecho ultraterreno de los reyes, su gracia divina $\mathrm{y}$, posteriormente, con las luchas revolucionarias, el advenimiento del sistema político democrático.

En su libro Consecuencias de la modernidad, Giddens señalaquelamodernidad poseeciertas discontinuidades que distinguen a las instituciones sociales modernas de los órdenes sociales tradicionales, a saber: «el ritmo de cambio», «el ámbito de cambio» y «la naturaleza intrínseca de las instituciones modernas». Con respecto a la primera discontinuidad, Giddens, alude a la celeridad del cambio inherente a las condiciones de la modernidad y que no estaba presente en las sociedades tradicionales. La segunda discontinuidad hace referencia a que, merced las interconexiones comunicacionales, ha sido posible que las agitaciones de transformación social se presenten en la totalidad del planeta. Finalmente, la tercera discontinuidad apunta la diferencia de las formas de organización social modernas con respecto a las tradicionales, es decir, un sistema político de Estados-nación, la mercantilización de los productos y del trabajo asalariado (producción capitalista sistemática) y el urbanismo moderno (Giddens, 2002).

Ahora, siguiendo la línea de Scoot Lash se pueden marcar otras características que denotan las diferencias entre lo que es moderno y lo que no. Lash argumenta que una sociedad tradicional corresponde a la Gemeinschaf (comunidad); lo que el denomina modernidad simple hace referencia a la Gesellschaft (sociedad). Aeste respecto, la Gesellschaft es moderna en el sentido de que la individualización ha quebrantado la vieja estructura tradicional -familia amplia, iglesia, comunidades- de la Gemeinschaf; y la sucesora de la modernidad simple es una modernidad reflexiva, en donde el motor del cambio social es la individualización, la auto-organización de las narrativas de vida y el posicionamiento de la flexibilidad laboral (Beck, 1998), (Giddens, 1994).

Otro de los autores que se involucra en la distinción de lo tradicional y lo moderno, es Jeffrey Alexander quien, haciendo una caracterización de las sociedades modernas, coincide con la opinión de Giddens, en que la modernidad surge de la ruptura sufrida por la sociedad medieval y, así, lo que hoy entendemos por modernidad está ligado al siglo de las luces, donde la modernidad empezó a identificarse con la racionalidad, la ciencia y el progreso. De esta manera, Alexander enlista los siguientes rasgos típico-ideales de la modernidad (Alexander, 2000).

1. Las sociedades se conciben como sistemas coherentemente organizados, cuyos subsistemas son fuertemente independientes entre sí.

2. La modernidad se define con referencia a la organización social y a la cultura de las sociedades específicamente occidentales que fueron tipificadas como individualistas, democráticas, capitalistas, y seculares. 
Tenemos entonces que la modernidad es un fenómeno característico de las sociedades complejas (desarrolladas, occidentales u occidentalizadas) en donde la existencia de sistemas expertos ${ }^{1}$ regula las interacciones entre individuos y también entre estos últimos y objetos materiales. Por tal, el desarrollo de dichos sistemas ha generado la individualización de la sociedad, en el sentido de que cada vez son menos necesarias las relaciones cara a cara, es decir, en nuestro moderno mundo de vida, la fiabilidad en los sistemas expertos nos permite trabajar en casa, estudiar posgrados en línea, hacer pagos en línea, asistir a conferencias que están tomando lugar en el otro lado del mundo, etcétera.

Con respecto al tiempo - espacio se puede aludir que con el desarrollo de las tecnologías, principalmente las de información, las interacciones sociales han adquirido una celeridad sin precedente. En nuestros días es preferible hacer transacciones bancarias desde nuestra casa o lugar de trabajo a través de Internet, que acudir al banco a «perder» dos horas de nuestro tiempo. La noción de tiempo ha cambiado. En la modernidad, los individuos están en la búsqueda de la maximización o mejor uso de su tiempo: «ahorrar tiempo» es una noción presente en el discurso cotidiano de los sujetos. Giddens hace referencia a que es importante la distinción entre estas dos nociones. Por una parte, el lugar tiene como características lo local y la presencia física en el desarrollo de actividades, mientras por otra, el espacio se caracteriza por actividades a distancia entre ausentes. En tales términos, los individuos en la modernidad ocupan cada vez más un espacio que un lugar.

El proceso de democratización de los Estados nacionales es otro componente de la modernidad. Se argumenta que cada vez tenemos sociedades más democráticas con considerables niveles de desarrollo en lo que a derechos civiles, políticos, ciudadanos y sociales se refiere. Esto puede ser constatable si posicionamos la mirada a finales del siglo XVIII en occidente, cuando germinó la lucha por los derechos mencionados.

\footnotetext{
${ }^{1}$ Sistemas de logros técnicos o de experiencia profesional que organizan grandes áreas del entorno material y social en el que vivimos. [5].
}

Empero, nuestra modernidad no es sólo progreso, bienestar, desarrollo y vida buena. A la par de la producción de todo lo anterior han surgido riesgos con los cuales ni siquiera el mismo proceso científico ha podido lidiar. Los grandes avances en el conocimiento del universo en que vivimos han generado amenazas ante las cuales el común de los humanos se ha quedado sin instrumentos para luchar. Nuestros días, se sugiere, son los de una modernidad reflexiva, donde, como ya se mencionó, el progreso también trae la destrucción. $\mathrm{Si}$ hasta este momento hemos constatado que la modernidad resulta ser un sinónimo de transformación, es de esperarse que otros conceptos hayan sufrido mutación. Beck es claro al mencionar que la palabra riesgo también ha cambiado en la modernidad, pues, la palabra riesgo en las sociedades tradicionales connotaba coraje o aventura y no la posible autodestrucción de la vida en la tierra (Beck, 1998).

Nuestra modernidad reflexiva es, entonces, una sociedad del riesgo en la cual han surgido fenómenos como las crisis ecológicas, sociales y económicas, el nacionalismo, el fundamentalismo religioso, la exclusión y la pobreza que amenazan ya no sólo a quienes se benefician o no del progreso, sino a la sociedad en su conjunto.

\section{La miseria es jerárquica, el smog es democrático}

Para entender el carácter central de los riesgos en el mundo moderno es necesario conocer a qué tipo de riesgos se encuentra expuesta la sociedad moderna, es decir, cuáles son las características que dan forma a este mundo que Giddens ha tildado de desbocado. En una modernidad reflexiva, el carácter de los riesgos está marcado por su alcance global y por la manera en que atentan no contra la integridad de un colectivo por su raza, estatus social o condición política, sino más bien contra la existencia del género humano y otras formas de vida en la tierra. Los riesgos en la modernidad reflexiva son omniabarcantes, no respetan categorías sociales, estratos económicos, el norte o el sur. Por lo regular, la quema de combustibles y la proliferación de procesos industriales generan dióxido de azufre, ácido sulfúrico, fluoruros y otro tipo de contaminantes que hoy son componentes bastante comunes de la mezcla atmosférica y con los cuales nos hemos acostumbrado a vivir. La contaminación del aire afecta, tanto a quien la produce, como a quien no contribuye con esa producción. 
En su libro La sociedad del riesgo, Beck elabora cinco tesis sobre los nuevos tipos de riesgo (Beck, 1998), de las cuales retomo cuatro ya que, por su contenido, ayudarán a despejar las dudas planteadas:

1.- Los riesgos que se generan en el nivel más avanzado del desarrollo de las fuerzas productivas (la radiactividad que se sustrae por completo a la percepción humana inmediata) se diferencian esencialmente de las riquezas. Estos riesgos causan daños sistemáticos y a menudo son irreversibles, suelen permanecer invisibles.

2.- Los riesgos de la modernización afectan tarde o temprano también a quienes los producen o se benefician de ellos. Contienen un efecto bumerang que hace saltar por los aires el esquema de clases.

3.- En las situaciones de clases y capas, el ser determina a la conciencia, mientras que en las situaciones de peligro la conciencia determina al ser.

4.- Lo que hasta el momento se había considerado apolítico se vuelve político. Surge un potencial político de las catástrofes.

La invisibilidad de los riesgos resulta ser una tesis bastante refutable, pues los riesgos inherentes a la modernidad son perceptibles y evitables. En este sentido, los contaminantes en el aire son perceptibles (en la Cd. de México, por ejemplo, las molestias respiratorias, la irritación de los ojos son frecuentes entre los habitantes) y la peligrosidad que representa una inversión térmica ${ }^{2}$ es evitable sólo si existen políticas dirigidas a disminuir los niveles de contaminación generados por grandes industrias, automóviles, etcétera. Empero, más atractiva resulta la tesis del sociólogo cuando alude al carácter irreversible de los riesgos, es decir, una vez manifestados no es posible volver a tener un entorno como el que era usual antes de que se presentasen.

\footnotetext{
${ }^{2}$ Normalmente, el aire caliente de la superficie terrestre asciende y el aire de la parte superior de la atmósfera-más frío- cae, con lo cual se crea una circulación natural que dispersa los contaminantes superficiales del aire. Una inversión ocurre cuando las capas de aire de la atmósfera inferior son más frías que las superiores. La circulación natural sufre una interrupción y tanto el aire superficial acumulado como los contaminantes del aire se concentran alrededor de sus fuentes. La inversión térmica es un fenómeno peligroso para la vida cuando hay contaminación porque al comprimir la capa de aire frío a los contaminantes contra el suelo la concentración de los gases tóxicos puede llegar hasta equivaler a 14 veces más. (Cfr. http://www.sagan-gea.org/hojared/hoja20.htm).
}

La segunda tesis es por demás interesante, pues nos muestra cómo la necedad e intransigencia sigue permeando en la toma de decisiones; nos muestra cómo la «racionalidad» de la modernidad continúa guiada por la lógica de maximización de beneficios (económicos) sobre cualquier otro interés. Ejemplo de ello es, de nuevo, la contaminación del aire. La emisión de gases carbónicos es un problema que amenaza la existencia de los seres humanos, sin importar si éstos viven en países desarrollados o en desarrollo. Sin embargo, aún sabiendo que el efecto que Beck denomina bumerang no respeta estratos sociales ni condiciones políticas y económicas, nos encontramos con el fracaso de arreglos políticos para disminuir la emisión de gases invernadero.

En la modernidad reflexiva, la conciencia (el conocimiento) determina el ser. Esto significa que somos lo que somos merced a la afectación que hemos experimentado de los riesgos y, para ello es decisivo el tipo de conocimiento (Beck,1998). Entre mayor conocimiento posee un individuo con respecto a los riesgos y contingencias de su entorno, su capacidad de actuar se potencia y, por tal, es mayor su cálculo del riesgo.

Finalmente, en la última tesis muestra los cambios en la política. En este sentido se invita a pensar en la reinvención de lo político, pues los riesgos a los que se enfrenta la modernidad han sobrepasado los límites y la posibilidad de acción de quienes, usualmente, estaban al frente en la resolución de las contingencias-gobierno e instituciones públicas-. En la modernidad reflexiva se hace patente el rebasamiento de lo político, de la incapacidad de los agentes para resolver los problemas que acompañan al desarrollo industrial.

Así, la «incapacidad» de las instituciones políticas (partidos políticos, corporaciones, etcétera) para dar solución a los efectos colaterales de la modernidad viene acompañada de un surgimiento no institucional de lo político, del regreso de los individuos a la sociedad (Beck, 1999). En la modernidad reflexiva, nuevos grupos de individuos no coorporatizados intentan influir en la construcción de las agendas políticas y sociales para, de esta manera, llenar el vacío generado por quienes parecen tener más interés en representar otro tipo de cuestiones (meramente de corte realista, es decir, fe en que más progreso y mayor velocidad en el mismo dará solución a los efectos colaterales del desarrollo 
tecnológico) y que son «incapaces» de legislar sobre aquéllas que son ya una amenaza evidente para la condición humana.

Hoy a pesar de que los side effects del desarrollo tecnológico son más divulgables y perceptibles (merced la inmediatez de los medios de comunicación y la evolución de los mismos efectos colaterales), el argumento de que las instancias públicas y gubernamentales han quedado rebasadas (ya que no cuentan con los instrumentos necesarios para actuar en caso de, por ejemplo, una inevitable crisis ecológica y nuclear, caso reciente tsunami Japón), induce a formular la siguiente pregunta: ¿qué tan valido resulta el argumento de que las instancias gubernamentales, hoy, son incapaces de regular una catástrofe ecológica, social, económica, nuclear o bacteriológica? ¿Cómo puede sustentarse esta aseveración si son ellas las que otorgan o no permisos, desregulan o no sus sistemas financieros, promulgan o no leyes para el desarrollo de complejos tecnológicos? Como menciona Keynes, lo inevitable jamás sucede. Aquí se inserta como una pieza de rompecabezas el argumento de Beck con respecto a que la conciencia determina el ser. En épocas actuales no se puede hablar de un desconocimiento de los efectos colaterales de, por ejemplo, la ratificación o no del protocolo para salvar el medio ambiente y, por tal de un rebasamiento de la política, pues finalmente quienes toman o no las decisiones siguen siendo los representantes de los Estados nacionales, empresas, corporaciones, etcétera. El lado oscuro ya se conoce desde tiempo atrás (hemos sido testigos de Chernobil, la crisis de los tigres asiáticos, el tsunami de Japón), por lo que el argumento de una inevitable catástrofe no parece muy convincente. Hay formas de evitar otras lluvias radioactivas y otro efecto dragón, es cuestión, entre otras cosas, de no olvidar la existencia de los otros.

Ahora, por otro lado, se podría hablar de que los efectos colaterales de la modernidad pos-industrial han sobrepasado la capacidad de acción de las sociedades actuales no por su inevitabilidad sino por su irreversibilidad. Eso suena más coherente. Hay daños irreversibles: ¿Qué podemos hacer, por ejemplo, con los que alguna vez fueron bosques y hoy son grandes complejos industriales?

Sin embargo, el argumento de la incapacidad o inevitabilidad con respecto a los efectos colaterales puede sostenerse en un contexto: aquel en donde quienes promueven la fe en el progreso y los indiscutibles beneficios que de él se derivan, obtendrán un costo de $o_{\text {oportunidad }}{ }^{3}$ más alto que si tomaran la decisión de no promover el desarrollo. El costo de oportunidad que, por ejemplo, representa para una empresa de granos básicos utilizar abonos dañinos para el ambiente, pero que en términos monetarios resulta más redituable utilizarlos, sería que «sacrificaría» la maximización de sus ganancias por la protección de la naturaleza. Lo anterior induce a cuestionar de nuevo si realmente resultan inevitables los riesgos de la sociedad moderna.

\section{CONCLUSIONES}

\section{El lado oscuro de la modernidad}

En la modernidad de inicios del siglo XXI, todos aquellos que se benefician del progreso tienen conocimiento de los tipos de recursos que no son renovables, del tipo de acciones que no se deben llevar a cabo para evitar un colapso financiero, del tipo de legislación que se debe promover para evitar la continua contaminación de los ríos, del tipo de acciones que se deben llevar a cabo para luchar contra un inesperado incendio forestal-que obviamente no es talar los árboles, para de esta manera evitar más incendios como alguna vez lo sugirió el ex presidente norteamericano George Bush (Office of the Press Secretary). En las acciones del ser humano, la inevitabilidad no es un argumento válido. Ésta sólo es factible en caso de, por ejemplo, huracanes o erupción de volcanes; es decir, acciones en las que el ser humano no interviene en el proceso del fenómeno (no se menciona la inevitabilidad de un terremoto pues, en ocasiones, éstos han sido generados por pruebas nucleares).

Luego entonces, la dualidad de nuestra modernidad no puede ser resuelta con argumentos como la incapacidad, la in-evitablidad o la in-visibilidad. Si se promueve el progreso es porque se está asumiendo el costo de oportunidad de tener bienestar, confort y en general, una «buena vida» devenida del progreso científico, pretendiendo «no» conocer cuáles serán los riesgos a los que también nos enfrentaremos.

La modernidad, así como la tradición, no es un fenómeno que genere riesgos inevitables, no debe ser una condición que estamos obligados a padecer, no debe

\footnotetext{
${ }^{3}$ El costo de oportunidad es el valor de un recurso en su mejor uso alternativo.
} 
estar entre sus acepciones el fatalismo thatcheriano de there's no alternative. La modernidad, al igual que cualquier otro fenómeno, tiene su lado oscuro que, en el caso que se ha discutido aquí, está representado por los riesgos. Entrar en el debate de que los peligros de la modernidad son fenómenos que no se tenían contemplados, resulta ser un insulto hasta para la ciencia y quienes la hacen. Esta idea puede sostenerse en el sentido de un experimento, pero más de dos siglos de industrialismo no son un experimento sino una experiencia de forma de vida. Ante esto no se puede hablar de paradojas de la modernidad. Las paradojas o contradicciones en el progreso no existen, el lado oscuro de la modernidad sí.

Corresponde a investigadores, científicos, académicos -como es el caso de quienes trabajamos en instituciones de educación superior tecnológica- informar a nuestra sociedad de la dualidad de la modernidad. Es necesario que desde nuestro trabajo académico enseñemos y difundamos un uso mas razonado de las nuevas tecnologías para que estas se utilicen en beneficio del ser humano, de la naturaleza, de nuestro mundo. Es importante fomentar estos valores en el ser humano, de vital importancia en este marasmo que provoca la inercia del lado oscuro de la modernidad.

\section{REFERENCIAS}

Giddens, A., y Lash, S. (1994). Reflexive modernization. Politics, Tradition and Aesthetics in the Modern Social Order. Stanford, Stanford University Press.

Giddens, A. (2002). Consecuencias de la modernidad. Madrid: Alianza.

Alexander, J. (2000). Sociología cultural. Formas de clasificación en las sociedades complejas. Barcelona: Anthropos.

Eliot, F. (1986). Professional powers: A study in the institutionalization of formal knowledge. Chicago, Chicago University Press.

Ulrich, B. (1998). La sociedad del riesgo. Hacia una nueva modernidad. Barcelona: Paidós.

Ulrich, B. (1999). La invención de lo político. Buenos Aires: FCE.

Office of the Press Secretary. Declaraciones del presidente acerca de la iniciativa de los bosques saludables, Recuperado de http://www.whitehouse. gov/news/releases/2003/05/20030520-2.es.html

\section{HITOS DE CIENCIAS ECONOMICO ADMINISTRATIVAS}

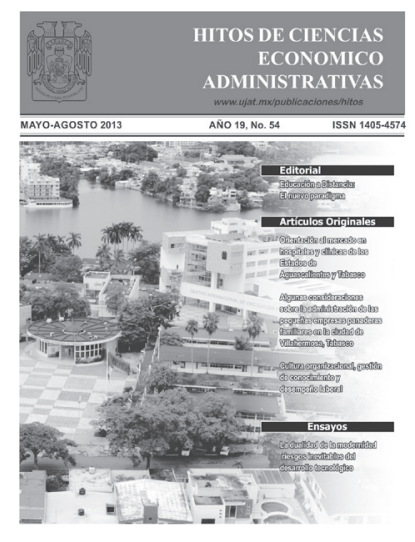

www.ujat.mx/publicaciones/hitos
Revista que publica cuatrimestralmente la DACEA-UJAT, se encuentra dentro del LATINDEX (Catálogo de Revistas Latinoamericanas) desde el mes de diciembre del año 2000, e indizada en CLASE (base de datos bibliográfica en Ciencias Sociales y Humanidades de la Universidad Nacional Autónoma de México) a partir del 23 de enero del 2001.

\section{http://www.dgbiblio.unam.mx}

Actualmente, nuestra publicación periódica está totalmente digitalizada y la puedes encontrar en la página WEB de la UJAT y es posible accesar a ella a través de: 